\title{
Theory inspired practice for end-of-life cancer care: An exploration of the McGill Model of Nursing
}

by David Kenneth Wright and Catherine Pugnaire Gros

\begin{abstract}
Nursing theories provide inspiration for practice by describing how to meet needs, enhance wellness, and respond to clients as whole persons. This paper discusses the McGill Model of Nursing with reference to how its ideas can support nursing practice for patients with cancer during the end-of-life phase. We suggest this model provides for a relational approach that is congruent with the philosophy of palliative care. The goal of this paper is to stimulate reflection amongst oncology nurses and nursing leaders. By comparing the value base of our practice against extant nursing theory, we may discover new opportunities for teaching and learning about what it means to be an end-of-life care nurse.
\end{abstract}

"If we allow this next generation of nurses to discard the relevance of nursing theory, a worry that has been expressed by recent observers, we may place the profession at considerable risk for losing its centre and its core purpose."

(Thorne, 2007, p.348)

Every oncology nurse is, or should be a palliative care nurse. Despite advances in medical innovation and prolonged survival times, cancer remains a life-limiting illness for many people. More than one quarter of all Canadians will die from cancer, with an estimated 75,000 deaths occurring in 2011 (Canadian Cancer Society's Steering Committee on Cancer Statistics, 2011). Of these, some will reach the end of their lives with unrelieved symptoms or unfulfilled wishes. The unmet palliative needs of terminally ill patients has been called a crisis in cancer care; a crisis that oncology nurses are well positioned to redress (Coyne, Paice, Ferrell, Malloy, Virani, et al., 2007).

Specialty certification in oncology nursing requires basic competency in end-of-life care (EOLC). Oncology nurses are expected, for example, to understand the unique needs of patients approaching end of life (EOL) and the goals of palliative treatment (Canadian Nurses Association, 2009). Unfortunately, not all nurses are equipped to properly care for such patients. The health care environments in which we deliver cancer care are oriented toward successful treatment and eventual cure of disease. While

\section{About the authors}

David Kenneth Wright, RN, MSc(A), CHPCN(C), Nursing Palliative Care Research and Education Unit, University of Ottawa School of Nursing, 451 Smyth, Ottawa, ON K1H 8M5. Dwrig079@uottawa.ca

Corresponding author: David Wright, 1-514-296-7069. Mailing address: 868 Sherbrooke E, Montreal, QC H2L 1K9

Catherine Pugnaire Gros, RN, MSc(A), Assistant Professor, McGill University School of Nursing, 3506 University Street, Montreal, QC H3A $2 A 7$ this approach is important and appropriate for many patients, it also focuses our collective attention away from the issue of death. Lack of familiarity with and attention to the process of dying can result in disengagement from and missed opportunity for our EOL patients.

"Palliative Care" is not a place, but a philosophy (Kessler, 2007). It is an approach that promotes quality of life, comfort, and wellness, and that responds to suffering in the context of life-limiting illness. The philosophy of palliative care affirms life while acknowledging the universality and normalcy of death. It advocates for the support of patients' family members and recognizes people as whole persons. Whole person care means offering integrated attention to the physical, as well as the psychological, social, and spiritual dimensions of health, illness, and dying (Pastrana, Junger, Ostgathe, Elsner, \& Radbruch, 2008).

The concept of palliative care is not new. What began and grew as a health care movement in the 1960s and 1970s is now an established medical subspecialty (Saunders, 2000). Palliative care has entered the discourse of oncology clinicians, and there is growing recognition of the need to incorporate palliative care into mainstream health care systems (Clark, 2007). Nurses are increasingly expected, therefore, to provide palliative care within large-scale institutions such as hospitals and long-term care settings. Indeed, the majority of Canadians die in such settings (Wilson, Truman, Thomas, Fainsinger, Kovacs-Burns, et al., 2009).

The current context of EOLC delivery can undermine a nurse's sense of professional identity and cause him or her to doubt the underlying philosophical bases on which good nursing practice is based. Within institutional settings that are not explicitly oriented toward care of the dying, the mandate to be efficient can sometimes override the mandate to care. Further, while much of palliative care discourse revolves around the telling of compelling "good-death" narratives that involve themes of peace, transcendence, and healing, we must be careful not to romantically distort the actual context of EOL caregiving. In their daily practice, nurses caring for the dying encounter pain, sadness, and suffering of tremendous proportion (Wright, Brajtman, \& Bitzas, 2009). They work with patients and families who are often angry, hurting, feeling guilty, and/or mistrusting.

Nursing theories address the philosophical underpinnings of our discipline. They offer explicit ideas about what nursing is and what role nurses play, and inspire practice through an articulation of how to meet needs, enhance wellness, and respond to clients as whole persons (Fitzpatrick, 2005; Meleis, 2007). Theoretical models of nursing provide a lens through which situations encountered in practice can be interpreted and better understood, and through which one's own response as a nurse can be analyzed and reflected upon. In this paper, congruence between ideas derived from one particular nursing theoretical approach, The McGill Model of Nursing, and the context of EOLC is considered. An examination of such congruence paves the way for reflecting on the practice possibilities within the field of EOL oncology nursing. 


\section{F. Moyra Allen and the McGill Model of Nursing}

Dr. F. Moyra Allen (1921-1996) was a prominent nurse leader, recognized across Canada and worldwide for her life's work that was inspired by a vision of "what nursing can be" (Stuart, 2002, p. 165). Allen devoted her career to developing an approach to nursing that would distinguish it from the work of all other health care providers (Gottlieb, 1995). Allen originally referred to this approach as the "Developmental Health Model", which later came to be known as the McGill Model of Nursing (MMoN) (Gottlieb \& Rowat, 1987). Allen believed that in the aftermath of the 1960s Canadian health care reform and the resulting call for nursing to take on an expanded role, our discipline was faced with a critical choice. We could expand into the field of medicine to take on knowledge and skill traditionally ascribed to physicians, or expand outward in developing a unique, complementary role that would focus on the development and maintenance of family health (Allen, 1977). Allen called for a shattering of the linear health-illness continuum on which mainstream biomedical thinking was based. For Allen, health and illness ought to be conceived of as separate variables: one is not merely the absence of the other. In her words, "health is not a static quality, it is a way of living, of being, it is a way of growing, of becoming" (Allen, 1981, p. 153). She believed that the framing of health as the absence of illness presented nursing with its most serious philosophical problem and logical dilemma. As the absence of illness, health "has no meaning of its own... One cannot work for or toward something that can only exist as not something else" (Allen \& Warner, 2002, p. 101, original emphasis).

This cursory biographical sketch illustrates the relevance of Allen's ideas to the field of EOLC nursing. While the focus of her writing does not address EOLC specifically, her vision of nursing involves the care and accompaniment of patients and families through all of life's transitions and developmental changes. Just as Allen was concerned with the medicalization of health, the philosophy of palliative care developed from a discontent with the medicalization of dying (Clark, 2002). This included the purportedly "violent" deaths that people were experiencing under a paradigm of resuscitative medicine (Carnevale, 2005, p.2). Palliative philosophy is premised on a notion of rescue, of saving dying patients and their families from a medical system that can be cold, impersonal, and overall antithetical to what people actually need, as they face EOL. For example, the need to be free of physical pain, the need to express feelings and emotions in personal ways, the need to be cared for with compassion, the need to seek spirituality, and the need to die in peace and with dignity (Kessler, 2007). Moyra Allen and the philosophy of palliative care share the view that illness, suffering and death are situations of human living through which personal and family learning, growth, and development (i.e., health) can occur. Health is a positive quality, and can exist within experiences of living-dying, loss, grief, and suffering (Canadian Hospice Palliative Care Association Nursing Standards Committee, 2009).

\section{The McGill Model of Nursing: Central concepts}

Central concepts of the McGill Model of Nursing (MMoN) include health, family, collaboration, and learning. Briefly, health is a multidimensional construct incorporating processes of coping and development and geared toward enhanced quality of life and the achievement of personal and family goals. Family is the context in which health is learned and, as such, represents a main focus of nursing assessment and intervention. Nursing care involves a process of collaboration in which patients and families are active participants in the health promotion process (Gottlieb \& Rowat, 1987).

The MMoN is primarily a learning model in that health promotion is viewed as a continuous process of inquiry and discovery (Pugnaire-Gros \& Young, 2007). Nursing according to the MMoN is a science of health promoting interactions (Pugnaire, 1981) through which nurses, patients, and families come together to learn about and work on situations of health and daily living (Allen \& Warner, 2002). The MMoN has recently been modified to include the "Developmental/Health Framework", a conceptualization that more fully articulates the nature of person and environment within the theoretical model originally proposed (Gottlieb \& Gottlieb, 2007). Driven by philosophies of whole person care, nursing practice according to the Developmental/Health Framework and the MMoN is strengthsbased. This involves recognizing, cultivating and optimizing positive aspects, attitudes, skills, and resources inherent in the person-family (Gottlieb \& Gottlieb, 2007). Clinical observations and experiences are interpreted through a language that emphasizes strengths and potential more than deficits or problems (Feeley \& Gottlieb, 2000).

\section{The McGill Model of Nursing: Ontology of personhood}

The MMoN holds that persons possess an inherent freedom to participate in their own health experience and to bear responsibility for the choices they make. According to the MMoN, persons are mindful, reflective, reciprocal, and flexible beings, who are ultimately "the architect of their own experience" (Gottlieb \& Gottlieb, 2007, p.E47). They are intrinsically driven toward regulation, attachment, and coping, because these forces are necessary for survival (Gottlieb \& Gottlieb, 2007).

The MMoN emphasizes the inseparability of the person from their environment, although environment does represent a discernible context in which individuals actualize their potential, reflecting a nature via nurture conception of human development. Nursing works to promote "goodness-of-fit" between individuals and their environments, thus facilitating successful adaptation (Gottlieb \& Gottlieb, 2007, p.E48).

Within the MMoN, a person is understood as invariably situated within a family context, and therefore the "unit of concern" from this perspective is the family (Gottlieb \& Rowat, 1987, p.55). Even when the nurse is interacting only with one person (e.g., the patient), the nurse perceives this person through a relational family lens, recognizing the reciprocal influence of the individual and family on each other. The individual and family are seen as "open systems in constant interaction with one another and with other systems in their environment" (Gottlieb \& Rowat, 1987, p. 55). The theoretical principle of linked lives expounds the fundamentally relational nature of human development and experience, emphasizing that people exist within a web of meaningful relationships. The theoretical model recognizes that:

"An individual's choices are often influenced by what has or is happening in the lives of others. Each individual follows his or her own developmental trajectory, and these trajectories are interlocked with other members in their social networks. When nursing understands this principle, the nurse expands and deepens the focus of care by working with multiple foci and through an intergenerational lens" (Gottlieb \& Gottlieb, 2007, p.E49). 


\section{The McGill Model of Nursing: Relationship to other nursing theories and models}

The MMoN shares features with other nursing theoretical ideas. Indeed, most existing nursing theories and nursing theoretical models share common values such as holism, humanization, meaning, quality of life, health, and comfort (Meleis, 2007; Willis, Grace, \& Roy, 2008). Diverse theoretical perspectives differ, however, in the emphasis placed on specific values and concepts and in how the primary focus and purpose of nursing is articulated. Meleis (2007) identifies four schools of thought that provide an orienting framework to the panoply of available nursing theories. According to her analysis, the first school of thought was developed by the needs theorists (e.g., Henderson, Orem). These theorists focused on problems, deficits and unmet needs in clients of nursing care. Second were the interaction theorists (e.g., Paterson and Zderad, Peplau). These theorists complemented the questions posed by the needs theorists and further focused their theoretical attention to the relationship between client and nurse. They posited nursing as an interpersonal process occurring between a person in need of help and a person capable of providing such help. Third were the outcome theorists (e.g., Johnson, Rogers, Roy). Their focus was on the why of nursing care, on the end results achievable through the nursing process. These theorists focused on the relationship of the client to their environment and situated the nursing role as providing for balance, stability, and adaptation. Finally, the caring/becoming theorists (Watson and Parse) introduced nursing as a relational activity of connection, dialogue, and presence.

According to Meleis's organization, the primary decision maker according to the first three schools of thought is the health care provider. In this way, the MMoN is similar only to the caring/becoming paradigm in its primary and fundamental emphasis on clients as the architect of their own experience and the ultimate decision maker in matters of concern to them. The MMoN departs from tenets of the caring/becoming school, however, in its consideration of coping and development as central theoretical concepts. Parse, for example, conceives of health as the living of personal value priorities, a personal commitment chosen by the client in his or her role as creative author (Parse, 1990). She writes that health "is not a linear entity that can be interrupted or qualified by terms such as good, bad, more, or less. It is not adapting to or coping with the environment" (Parse 1998 , p.32, original emphasis). According to the MMoN, people do progress toward better health through processes of coping and development. Coping is how people respond to situations and development involves the achieving of life goals (Gottlieb \& Rowat, 1987).

The uniqueness of the MMoN, when considered against the backdrop of other existing nursing theories, is discernible in its use of a learning framework for nursing and health promotion, and its emphasis and organization of specific concepts. The MMoN advocates for a practice philosophy that is all-atonce patient and family focused, situation responsive, and collaborative. Its emphasis on family-centred care is congruent with articulated philosophies of family nursing (e.g., Wright \& Leahey, 2005). The MMoN positions the nurse as a learner, partner, and supporter as clients navigate their health and illness journeys. The role of the nurse is to help people progress toward enhanced wellness and quality of life according to terms that they themselves define.

\section{Example from clinical practice}

"...one day I worked with a young woman with very advanced cancer. I had never in my life seen anyone so completely emaciated. There was something about this womanan incredible spirit. I was caring for her during the morning, and close to noon I just spontaneously said, 'You know, you have such an incredible spirit about you.' At the same time I said this, I was also thinking, 'How ironic that this tired flesh exudes such warmth and such a spirit.' So she, with difficulty, went over to her desk and pulled out a sealed envelope. She showed me a picture of her that had been taken 10 months earlier. She was a voluptuous, curvy woman in a bathing suit, smiling on vacation. That was her way of saying, 'This is who I am.' The spirit that I had observed was captured in the photo. This was our starting point for talking about the many changes she had experienced. The biggest change was the incredible change in her physical appearance. I quickly learned from this discussion that her goal was not to become bitter. She said, 'I don't want to become bitter about this, I want to stay who I am, maintain that spirit, the essence of who I am despite what you see on the outside.' I had just met this woman when this encounter occurred, but because I was able to get to know this woman and her goals quickly, our collaborative relationship continued for a couple of weeks." (Gottlieb \& Feeley, 2005, p. 114; passage by palliative care nurse Heather Hart).

In this example, the nurse is open to being amazed by her patients. She identifies the strength of spirit in a woman who might otherwise be seen only as sick, weak, and dying. Offering up this strength through commendation opens a space for further learning and exploration. The patient chooses to share her photograph and to engage in reflective dialogue concerning the changes she has experienced. Through this process, the nurse comes to understand her patient, gaining insight into her priorities and discovering her health goal.

This example is powerful because it illustrates how a nursing approach oriented toward cultivating strengths and fostering collaboration results in knowing the client on a radically different level than would be possible otherwise. Understanding this dying woman's own goal can then provide direction in planning and delivering care that will be truly patient-centred.

\section{Integrating the McGill Model of Nursing into end-of-life care}

In the following sections, two dimensions of the MMoN practice philosophy are discussed with explicit reference to the context of EOLC: 1) transitions and readiness, and 2) family-centred care.

\section{Transitions and readiness}

The concepts of situational and developmental life transitions, while applicable to nursing in general, are of special significance to an EOL context. According to Twycross (2007), the basic goal of EOLC is to help patients and families transition from "fighting death to seeking peace" (p.9). Boundaries between pure "curative" approaches (disease modifying therapy with the goal of prolonging life) and pure "palliative" approaches (symptom modifying therapy with the goal of enhancing life's quality) are, however, never absolute or clear-cut. For example, many oncology patients receive anti-cancer treatments that are designed to enhance quality of life and even prolong survival, but not cure the disease. Nurses play a central role in helping patients and families navigate the delicate and gradual shift in care focus as disease progresses and death approaches. 
According to a grounded theory study that explored the determinants of quality EOLC from the perspective of hospital nurses, "creating a haven for safe passage" is an overarching theme of quality EOLC (Thompson, McClement, \& Daeninck, 2006, p.92). Several obstacles to transitioning successfully ("changing lanes" from curative to palliative care) were identified in this study. These include: 1) death denial by nurses, physicians, patients, and families, 2) difficulty in accurate prognostication, and 3) divergent perspectives on what quality EOLC actually means in care settings. Conversely, when patients, families, and health care providers are all cognizant and accepting of impending death, successful transition is facilitated:

“...nurses, physicians, patients, and family members must clearly understand that the individual will not recover from their illness and that the prognosis is dire...when patients and their families clearly understand the nature and prognosis of the illness, and when end-of-life discussions occur while the patient is still capable of participating in decision making, nurses said changing lanes occurs much more swiftly and smoothly" (p.95).

The nurse participants in this study speak to an important role for nursing in accompanying patients and families in their journey toward EOL, which includes softening the burden of impending loss through information and support. They are less vocal, however, on how best to help patients and families who are not ready, willing, or interested in expressing acknowledgement of impending death. For some, engaging with health professionals around acceptance of their own dying or the dying of a family member may not be a good fit with their needs. Perhaps too often, nursing seems to impose a tremendous expectation on terminally ill patients and families to let go in the face of inevitable dying (Lowey, 2008). On the other hand, we seem less skilled at practising tolerance and respect for divergent coping styles of hope, avoidance, or denial. What we identify as problematic, however, may actually be the best fit for particular patients and families. A recent study by Sjolander, Hedberg and Ahlstrom (2011) reports that some families band together to banish thoughts about impending loss in the context of an advanced cancer diagnosis. These families "do not know how long the person is going to live, nor do they really want to know" (p.3-4, original emphasis). Indeed, a good death is highly individualized and variablewhile one person's good death may involve relinquishment, acceptance, and peace, another's may depend on being able to claim that they clung to life until the very last breath. As Quill, Arnold, and Back (2009) observe:

"Some patients and families may value life extension much more highly than avoiding preventable suffering, others may not trust the medical system enough to forgo any treatment, and still others may be unwilling to confront the possibility of dying. Once the patient's philosophy is clearly articulated in favor of all possibly effective treatments no matter how harsh or invasive, continuing to negotiate around limit setting is unlikely to be productive and may feel abusive" (p.348).

Nursing practice inspired by the MMoN operates explicitly within a framework of situation responsive practice in which interventions are tailored to achieve goodness of fit and timed in response to client readiness (Dalton \& Gottlieb, 2003; Gottlieb $\&$ Feeley, 2005). As persons and families contemplate change, nurse and client engage in a process of collaborative reflection. Interventions include reframing issues that might be considered in a new light, raising awareness through pointing out similarities and differences across situations, and pointing out observed changes (Gottlieb, 1997). As families journey through the transition to EOL and are offered palliative "comfort" care as a therapeutic option, the nurse might, for example, reframe a belief that palliative care means "nothing more can be done" to a perspective that palliative care involves aggressive symptom management and close and consistent accompaniment for patient and family.

The nurse practising from a MMoN perspective understands that patients and families may be ready to change some aspects of their situation, but not others; readiness is both a state and a process. This realization is crucial to effective EOL nursing practice since palliative care is not an all-or-nothing approach. Rather, it represents a complex landscape of daily living in which people continue to make decisions about various aspects of their care and their lives. Indeed, there is great variation within families and within individuals as to the degree to which they "fight death" and "seek peace" as death approaches. As nurses, we should continually be asking ourselves where the patient and family are "at", and what we can do, together, to be most supportive and helpful at this current point in time. Patients and families in EOL situations are empowered and can maintain or regain a sense of control through nursing interventions that open space for them to grieve their losses, cope with an uncertain future and celebrate their successes and accomplishments in life.

Understanding the concept of readiness within the MMoN means that nurses "assess readiness to help prepare clients for health work, ... create the necessary conditions to foster readiness, and ... assume the roles that help them prepare to change" (Dalton \& Gottlieb, 2003, p. 115). The MMoN suggests that nurses working with patients and families at EOL follow the client's lead regarding the extent to which working toward accepting impending death, through conversation, problem solving and decision-making, is actually desirable and helpful. Rather than urging patients and families to acknowledge and confront their situation, the nurse focuses instead on her own attitude, accepting her client and mirroring his/her coping style. This approach is illustrated in the following clinical narrative recounted by an oncology nurse caring for a young man from northern Alberta:

"He just didn't use many words. It wasn't his way. I knew that talking would be too much for him. It wasn't needed. When I watched his family around him, especially his Mom whom he loved very much, they just were very quiet. They just sat with him. So when I was his nurse I tried to mirror my behaviour to theirs...[to] show respect for the ground he stood on, for his culture, his ways..." (Perry, 1998, p. 22).

In this example, trusting the patient and family as experts in matters of concern to them and honouring who they are and what they are doing at that moment in time is the focus of care. The nurse makes herself available and provides accompaniment. She offers her expertise where indicated, and does not impose an unwelcome agenda. Acceptance on the part of the nurse means discovering and embracing what is unique to a particular client and family, offering presence and intervention through the use of a wait and see strategy (Feeley \& Gottlieb, 1998).

\section{Collaborative, family-centred nursing}

A family-centred perspective is fundamental to EOLC nursing (Chekryn Reimer, Davies, \& Martens, 1991). Supporting families during the terminal phases of patient illness has a positive effect on adjustment to bereavement (Dumont, Dumont, \& Mongeau, 2008). As Fanslow-Brunjes (2008) notes: 
"the dying and their family and loved ones [need to] be considered as a single unit, much as mother and child are often addressed as one. They should be seen in this way because, in a unique and special way, they are all dying" (p. 81).

Further, orienting ourselves toward the perspective and needs of family is a way of demonstrating respect for the individual patient. By honouring the relationships and the people that are significant to him or to her, we recognize and acknowledge our client as a relational being for whom other people have mattered and who still matters to other people*.

Although care for the family is generally understood as integral to palliative care philosophy, family-centredness is sometimes more of an ideal than a practice reality (Kristjanson \& Aoun, 2004). Theoretical models of nursing that emphasize the importance of family are, therefore, valuable to EOL practice in that they broaden our understanding of the individual patient who is invariably situated within a unique family context. In addition, family-centred approaches enable nurses to respond directly to family members who have their own unique needs for support in EOL situations.

Although most conceptualizations of nursing deal in some way with family, the MMoN includes family relationships in its very conceptualization of person (recall the concept of linked lives). According to Gottlieb and Gottlieb (2007):

"[Moyra] Allen proposed that the unit of care was the family rather than just the individual because it is in the family that individuals learn about health (i.e., how to cope) and that all problems are a phenomenon of the family. In our reconceptualization, the focus of nursing attention is both the individual and the family; the individual within the context of the family, as well as the family as a unit of care. Family is defined in the [MMoN] as any individual that the patient identifies as family. Although the nurse does not always work with the family as a unit, the nurse is "family minded" and many nurse-patient interactions are, at the very least, considered through a family lens where relevant and appropriate" (p.E54-55).

The MMoN is explicit in outlining collaborative partnership with families as a key feature of the nursing relationship (Gottlieb \& Rowat, 1987). A collaborative partnership involves nurse and family working together toward mutually defined goals, through processes of power sharing and negotiation (Gallant, Beaulieu, \& Carnevale, 2002). The MMoN approach to care assumes that families have within them inherent strengths and resources that equip them to deal with health challenges (Feeley \& Gottlieb, 2000). Specific nursing strategies to promote family-centred, strengths-based, collaborative practice, based on the MMoN, include actively soliciting the family's perspective and beliefs, and helping family members explore, clarify, and prioritize their needs and values. This approach to nursing involves openness and respect for the family, and an attitude that is accepting, flexible, and free of negative judgment (Gottlieb \& Feeley, 2005).

Collaboration with patients and their families is the cornerstone of effective EOL nursing practice. Just as the patient requires care, family members must also be nursed and cared for during what also represents a time of transition and change for them (Chekryn Reimer, Davies, \& Martens, 1991). Further, oncology nurses are often working with families of patients who can no longer speak for themselves (e.g. comatose, sedated, or imminently dying patients). In these situations, families become an important asset to the nurse who comes to know the patient through the family (e.g., their personality, their biography, their preferences, their values).

Family intervention involves supporting family participation in the care of their loved one and supporting family involvement in decision-making. At EOL, choices are made on a continuous basis, and families invariably are part of this decision-making process. Families, too, are the ones who have to live with the decisions made after the patient dies. Examples include decisions about pain management, about how to respond to various conditions as they arise (e.g., infection, dehydration/malnutrition, metabolic disturbance), and about whether to talk or not talk with the patient about impending death (Callanan, 2008). Other less "dramatic" decisions are also made continuously, as nursing care of the dying loved one is organized, and families generally appreciate having their input in these decisions heard. For example: should the nurse turn and position the patient now or come back later? Would it be best to help bathe the patient in the morning or the evening?, and so on.

Family members are not a homogeneous entity, but rather a diverse group of people with multiple voices, perspectives, and interests (Meiers \& Brauer, 2008). Nurses working with families at EOL, then, are operating within a landscape of multiple truths and realities; there is no single correct way to view a problem or situation (Leahey \& Harper-Jaques, 1996). The MMoN perspective is helpful to nursing in this context because it prioritizes the development of caregiving partnerships with family members. Through these relationships, divergent perspectives are invited, shared, and explored. This involves learning from families through interventions such as listening and asking pertinent questions, rather than acting as expert and telling families what to do (Gros \& Ezer, 1997). The nurse focuses on learning to trust the family instead of trying to get the family to trust the nurse (Pugnaire-Gros \& Young, 2007). Thus, by engaging in a process of discovery and learning together, the nurse practising from a MMoN perspective works with family members in a manner that mirrors her approach to the individual patient (Gros \& Ezer, 1997).

Working with families in EOL situations is not easy or straightforward. Nurses may experience difficulty accepting or even understanding family members' attitudes, behaviours, or approaches (Wright et al., 2009). Families may "interfere" with the care that the nurse is trying to deliver (e.g., prohibit administration of medication that is intended for patient comfort). This can be a source of great frustration for the nurse, who may respond by adopting a confrontational or avoidant relational stance. As Cicely Saunders reminds us, however, how people die remains in the memories of those who live on. The nursing that we deliver in the final months, days, hours, and minutes of someone's life will become part of the stories that are told and retold by family, as they construct and live their bereavement. Oncology nurses have an ethical mandate to tailor their nursing care in a way that is helpful and supportive to family, as well as to the individual patient. A theoretical framework that centres family moral experience as a phenomenon of concern to nursing practice is helpful in this regard. As the following quote suggests, dying can produce horrific scenes that will be remembered. Staying-with and bearing witness to suffering are fundamental to creating a safe context for dying that is lived by the patient and by the family.

\footnotetext{
*For certain patients, family members may not be present. For others, there may be no family at all. This discussion on "family-centred nursing" refers to nursing people who present themselves as having an interest in the well-being of the patient and/or whom the patient would identify as significant to her/his life.
} 
"She was so ill. She was bleeding to death in front of my eyes and there was little I, or anyone could do. As I helped her back to bed, her three beautiful teenage sons pressed closer to the wall and watched in horror. ... I sat down on her bed and took her hand tightly in mine. Putting aside all thoughts... I let my energy flow into her. As silent seconds passed I felt some of her spirit pour into me. At that moment, I was changed. At that moment, I became a nurse" (Perry, 1998, p. 11).

\section{Discussion}

The MMoN inspires nurses working with patients dying of cancer and their families to adopt a relational approach that is congruent with palliative care philosophy. The nurse positions herself as a comfort, support, and consistent presence who, rather than imposing an agenda, offers accompaniment, respect, and understanding. This relationship becomes the context through which mutual learning and discovery occur. The nurse is kind, open, flexible, curious, and invested. She embodies and works toward actualizing the basic values that ground the MMoN: collaboration, strengths-based practice, and learning together with patients and families across situations of daily living encountered at EOL.

Ideas from the MMoN provide material for discussion and debate amongst oncology nurses about the meanings and place of collaborative family-centred nursing, working with patients and families experiencing transitions, and ultimately, about how to best serve the communities in which we practise. The collaborative and situation-responsive nature of nursing described within the MMoN, as applied to nursing practice at EOL, might inspire in us a sense of humility around notions of good deaths and our role in facilitating these. We may believe strongly in our own ideas about what a good death can mean. We may also feel confident that our experience has qualified us to coach patients and families towards their own good death experiences. Nevertheless, we should be mindful of our place in the dying experience of others. Ultimately, our role is to effectively convey that the dying people and families trusted to our care matter to us, and that we are committed to helping them live out their EOL experience in their own way, according to their own terms. These ideas are illustrated in the following reflection of an oncology nurse:

"Making the patient feel like they are the most important person in the world, even if it's just for the moments you are with them, that should be our goal... that has been my goal... It's the little things that make a patient feel important, like the way you enter a room. I consciously slow down my pace as I enter. I take time to sit down in the patient's room and really listen to their concerns...You just let them know that they still matter. Even if it is just for this moment, you matter" (Perry, 1998, p. 119).

\section{Conclusion}

Delivering holistic and integrated care to patients and families, as they live through the cancer care continuum, requires collaboration between oncology and palliative spheres of nursing practice. Oncology and palliative nurses have much to teach and learn about each other as they attempt to meet the complex needs of their advanced cancer patients. Palliative care philosophy, which essentially is a set of ideas about acknowledging death and working toward quality of life through holistic, person-/family-centred care, can be appropriately adopted by all nurses working in oncology settings. Using the MMoN as a guiding framework, oncology nurses can discover new ways to practise such that they remain faithful to and focused on the underlying philosophy of palliative care, which is ultimately about being as helpful as possible to people living through EOL situations.

\section{Acknowledgement}

We thank Andrea Witkowski, RN, MSC(A), CON(C), for her thoughtful comments and feedback on an earlier version of this paper.

\section{REFERENCES}

Allen, M. (1977). Comparative theories of the expanded role in nursing and implications for nursing practice: A working paper. Nursing Papers, 9, 38-45.

Allen, M. (1981). The health dimension in nursing practice: Notes on nursing in primary health care. Journal of Advanced Nursing, 6, 153-154.

Allen, F.M., \& Warner, M. (2002). A developmental model of health and nursing. Journal of Family Nursing, 8(2), 96-135.

Callanan, M. (2008). Final journeys. A practical guide for bringing care and comfort at the end of life. New-York, NY: Bantam.

Canadian Cancer Society's Steering Committee on Cancer Statistics. (2011). Canadian Cancer Statistics 2011. Toronto, ON: Canadian Cancer Society. Retrieved from http://www. cancer.ca/Canada-wide/About\%20cancer/Cancer\%20statistics. aspx?sc_lang=en

Canadian Hospice Palliative Care Association Nursing Standards Committee. (2009). Canadian hospice palliative care nursing standards of practice. Retrieved from http://www.chpca.net/ interest_groups/nurses_ig.html

Canadian Nurses Association. (2009). Oncology nursing certification: exam blueprint and specialty competencies. Retrieved from http://www.cna-aiic.ca/CNA/documents/pdf/publications/ CERT_Oncology_2009_e.pdf

Carnevale, F.A. (2005). The palliation of dying: A Heideggerian analysis of the "technologization" of death. Indo-Pacific Journal of Phenomenology, 5(1), 1-12.

Chekryn Reimer, J., Davies, B., \& Martens, N. (1991). The nurse's role in helping families through the transition of "fading away". Cancer Nursing, 14(6), 321-327.

Clark, D. (2007). From margins to centre: a review of the history of palliative care in cancer. Lancet Oncology, 8, 430-438.

Clark, D. (2002). Between hope and acceptance: the medicalisation of dying. British Medical Journal, 324, 905-907.

Coyne, P., Paice, J.A., Ferrell, B.R., Malloy, P., Virani, R., \& Fennimore, L.A. (2007). Oncology end-of-life nursing education consortium training program: Improving palliative care in cancer. Oncology Nursing Forum, 34(4), 801-807.

Dalton, C.C., \& Gottlieb, L.N. (2003). The concept of readiness to change. Journal of Advanced Nursing, 42(2), 108-117.

Dumont, I., Dumont, S., \& Mongeau, S. (2008). End-of-life care and the grieving process: family caregivers who have experienced the loss of a terminal-phase cancer patient. Qualitative Health Research, 18(8), 1049-1061.

Fanslow-Brunjes, C. (2008). Using the power of hope to cope with dying. The four stages of hope. Sanger, CA: Quill Driver Books.

Feeley, N., \& Gottlieb, L.N. (2000). Nursing approaches for working with family strengths and resources. Journal of Family Nursing, 6(1), 9-24.

Feeley, N., \& Gottlieb, L.N. (1998). Classification systems for health concerns, nursing strategies and client outcomes: Nursing practice with families who have a child with a chronic illness. Canadian Journal of Nursing Research, 30, 45-59. 
Fitzpatrick, J.J. (2005). Nursing knowledge development: Relationship to science and professional practice. In J.J. Fitzpatrick, \& A.L. Whall (Eds.), Conceptual models of nursing. Analysis and application (4th ed., pp.1-4). Upper Saddle River, NJ: Pearson Education Inc.

Gallant, M.H., Beaulieu, M.C., \& Carnevale, F.A. (2002). Partnership: An analysis of the concept within the nurse-client relationship. Journal of Advanced Nursing, 40(2), 149-157.

Gottlieb, L.N. (1997). Health promoters: Two contrasting styles in community nursing. In L.N. Gottlieb, \& H. Ezer (Eds.), $A$ perspective on health, family, learning, and collaborative nursing. A collection of writings on the McGill model of nursing. (pp.87100). Montreal, QC: McGill University School of Nursing.

Gottlieb, L.N. (1995). A blueprint for the development of the profession of nursing: The legacy of F. Moyra Allen and Joan Gilchrist. Canadian Journal of Nursing Research, 27(3), 5-7.

Gottlieb, L.N., \& Feeley, N., with Dalton, C. (2005). The collaborative partnership approach to care. A delicate balance. Toronto, ON: Elsevier Canada.

Gottlieb, L.N., \& Gottlieb, B. (2007). The developmental/health framework within the McGill model of nursing: "Laws of nature" guiding whole person care. Advances in Nursing Science, 30(1), E43-E57.

Gottlieb, L., \& Rowat, K. (1987). The McGill model of nursing: A practice-derived model. Advances in Nursing Science, 9(4), 5161.

Gros, C., \& Ezer, H. (1997). Promoting inquiry and nurse-client collaboration: A unique approach to teaching and learning. In L.N. Gottlieb, \& H. Ezer (Eds.), A perspective on health, family, learning, and collaborative nursing. A collection of writings on the McGill model of nursing. (pp.219-225). Montreal, QC: McGill University School of Nursing.

Kessler, D. (2007). The needs of the dying. A guide for bringing hope, comfort, and love to life's final chapter. (10th Anniversary ed.). New-York, NY: Harper Collins Publishers.

Kristjanson, L.J., \& Aoun, S. (2004). Palliative care for families: Remembering the hidden patients. Canadian Journal of Psychiatry, 49, 359-365.

Leahey, M., \& Harper-Jaques, S. (1996). Family-nurse relationships: core assumptions and clinical implications. Journal of Family Nursing, 2(2), 133-151.

Lowey, S. (2008). Letting go before death: A concept analysis. Journal of Advanced Nursing, 63, 208-215.

Meiers, S.J., \& Brauer, D.J. (2008). Existential caring in the family health experience: A proposed conceptualization. Scandinavian Journal of Caring Sciences, 22, 110-117.

Meleis, A.I. (2007). Theoretical nursing. Development and progress. (4th ed.). Philadelphia, PA: Lippincott Williams \& Wilkins.

Parse, R.R. (1990). Health: A personal commitment. Nursing Science Quarterly, 3(3), 136-140.

Parse, R.R. (1998). The human becoming school of thought. A perspective for nurses and other health professionals. Thousand Oaks, CA: Sage Publications.
Pastrana, T., Junger, S., Ostgathe, C., Elsner, F., \& Radbruch, L. (2008). A matter of definition-key elements identified in a discourse analysis of definitions of palliative care. Palliative Medicine, 22, 222-232.

Perry, B. (1998). Moments in time: Images of exemplary nursing care. Ottawa, ON: Canadian Nurses Association.

Pugnaire, C. (1981). Nursing: the Science of Health-Promoting Interaction. Unpublished Master's study School of Nursing, McGill University, Montreal, Canada.

Pugnaire-Gros, C., \& Young, L.E. (2007). Teaching the McGill model of nursing and client-centred care: Collaborative strategies for staff education and development. In L.E. Young \& B.L. Patterson (Eds.), Teaching nursing: Developing a student-centred learning environment (pp.189-220). Philadelphia: Lippincott Williams \& Wilkins.

Quill, T.E., Arnold, R., \& Back, A.L. (2009). Discussing treatement preferences with patients who want "everything". Annals of Internal Medicine, 151, 345-349.

Saunders, C. (2000). The evolution of palliative care. Patient Education and Counseling, 41, 7-13.

Sjolander, C., Hedberg, B., \& Ahlstrom, G. (2011). Striving to be prepared for the painful: Management strategies following a family members' diagnosis of advanced cancer. BMC Nursing, 10(18), 1-8. doi:10.1186/1472-6955-10-18

Stuart, M. (2002). F. Moyra Allen: A life in nursing, 1921-1996. Journal of Family Nursing, 8(2), 157-165.

Thompson, G.N., McClement, S.E., \& Daeninck, P.J. (2006). "Changing lanes": Facilitating the transition from curative to palliative care. Journal of Palliative Care, 22(2), 91-98.

Thorne, S. (2007). Conceptualizing the purpose of nursing: Philosophical challenges in creating meaningful theoretical learning experiences. In L.E. Young \& B.L. Patterson (Eds.), Teaching nursing: Developing a student-centered learning environment (pp.347-363). Philadelphia: Lippincott Williams \& Wilkins.

Twycross, R. (2007). Patient care: Past, present, and future. Omega: The Journal of Death and Dying, 56(1), 7-19.

Willis, D.G., Grace, P.J., \& Roy, C. (2008). A central unifying focus for the discipline: Facilitating humanization, meaning, choice, quality of life, and healing in living and dying. Advances in Nursing Science, 31(1), E28-E40.

Wilson, D.M., Truman, C.D., Thomas, R., Fainsinger, R., KovacsBurns, K., Froggatt, K., et al. (2009). The rapidly changing location of death in Canada, 1994-2004. Social Science \& Medicine, 68, 1752-1758.

Wright, D., Brajtman, S., \& Bitzas, V. (2009). Human relationships at the end of life: An ethical ontology for practice. Journal of Hospice and Palliative Nursing, 11(4), 219-227.

Wright, L.M., \& Leahey, M. (2005). Nurses and families. A guide to family assessment and intervention. (4th ed.). Philadelphia, PA: F.A. Davis Company. 